\title{
A JOSÉ ANTONIO SAMPER. EN MEMORIA DE UN HOMBRE NOBLE, DE UN SABIO GRANDE
}

Todavía cuesta creerlo. Aunque pasan los meses, uno no acaba de dar nada por cierto y piensa, ingenuamente, que seguramente no es así. Pensamos esperanzados que cuando pase este tiempo sin abrazos ni reencuentros, este tiempo en el que extrañamos a tantos, también nos volveremos a encontrar con José Antonio, con su figura serena y amable, con su saludo carińoso y transparente. Pero no. Definitivamente no será así. Y no lo será porque el último diciembre fue más frío que de costumbre desde que atravesó nuestras vidas la noticia de su partida, una de esas noticias de las que duelen por dentro. Sabíamos de su enfermedad, pero también de la entereza y la serenidad con la que le hizo frente y sabíamos que iba ganando la pechada hasta que todo se precipitó para que el día de Santa Lucía nos trajera la tristeza de un adiós, de esos que nunca querríamos tener que dar. Quiso el destino que todo sucediera en ese exacto momento en el que toca ir desprendiéndose de las obligaciones laborales para colocar en primer lugar las devociones que, en el caso de profesionales como José Antonio, suelen coincidir con exactitud. No deja de hacer más doloroso el adiós que este llegue en el momento en el que a uno le toca, después de tanto sembrar, disfrutar de la cosecha floreciente y ver el fruto del trabajo bien hecho en el camino andado y en los rumbos que van abriendo los discípulos. Pero nunca elegimos cuándo y quizá por ello haya que vivir con esa intensidad con la que José Antonio vivió su profesión, su hondo convencimiento vocacional y su pasión docente e investigadora para no marcharnos del todo cuando nos toque irnos, para quedarnos en las huellas que habrán de alumbrar otros rumbos.

Voces más autorizadas que la mía, especialistas en los campos que dominaba el profesor Samper, pueden glosar convenientemente, como además ya han hecho, incluso con sentidas y rigurosas necrológicas, su sólida trayectoria profesional. Baste decir que estamos ante un nombre imprescindible en la filología y más concretamente en la sociolingüística hispánica que, además de otros muchos méritos, ha colocado a Canarias y específicamente a la Universidad de Las Palmas de Gran Canaria en una posición referencial, circunstancia a la que han aportado lo mejor de sí todos los profesionales de los equipos con los que trabajó durante sus ańos universitarios, empezando por quienes quedan más cerca de su corazón: Clara Eugenia Hernández y Marta Samper, primeras continuadoras de su trabajo y custodias de un legado luminoso. Además, son muchos los años en los que José Antonio dejó su impronta en diferentes cargos entre los que destacaría la dirección del Departamento de Filología Española, Clásica y Árabe de la Universidad de Las Palmas de Gran Canaria y la presidencia de la Academia Canaria de la Lengua, cuya 
vicepresidencia ostentaba en el momento de su adiós y a la que contribuyó decididamente tanto con su convencido trabajo investigador y divulgativo como con su gestión constante y comprometida. $\mathrm{Y}$ a todo ello sumemos al profesor, al que tuve la suerte de conocer como alumno, suerte que acrecenté posteriormente al formar parte como profesor de literatura del departamento que dirigía y al ingresar bajo su presidencia en la Academia Canaria de la Lengua. José Antonio fue un profesor ejemplar, de esos que te hacen tirar del hilo de la curiosidad y que hacen que los supuestamente convencidos y futuros filólogos interesados prioritariamente en la literatura, como era mi caso, estuviéramos a punto de sucumbir a los encantos de la otra mitad de nuestro objeto de estudio, novedosa y rigurosamente tratada en una asignatura, sociolingüística, que embellecía y prestigiaba una licenciatura a la que complementaba equilibrada y sabiamente (como en la vida) la dialectología rigurosa y apasionadamente enseñada por Clara Eugenia Hernández. Ambos abrieron ante aquellos ávidos estudiantes de la antigua licenciatura en Filología Hispánica un horizonte apasionante lleno de nombres que no han dejado de acompañarnos, que iban a parar a la pizarra o a los apuntes y que, con mucha frecuencia, nos visitaban en el aula para sentir aun mayor orgullo por unos docentes que hacían y hacen verdadera enseñanza universitaria, enseñando en sus clases el fruto de su trabajo y dándole a la investigación su verdadero sentido al transferirla al aula y multiplicar con ello su impacto, que no está en los índices, como quiere creerse, sino en la curiosidad y el interés que somos capaces de despertar en quienes nos siguen, algo más difícil de medir pero sin duda más meritorio. Otro detalle no menor que me permito destacar de José Antonio, tan respetuoso y atento con sus maestros como con sus discípulos, es su capacidad para abrir rumbos, como los que otros abrieron para él, a los que han ido a su lado creando una escuela que es, sin duda, el mayor legado que un profesor universitario puede dejar y que en su caso es mucho más que una evidencia.

Y siempre, en el centro de su trabajo, el rigor, sin duda alguna una herramienta innegociable para quien quiera adentrarse en los caminos universitarios y especialmente para quien lo haga en las disciplinas en las que solo los datos pueden confirmar las hipótesis, en las que solo midiendo los resultados podremos llegar a conclusiones veraces. En cuántas ocasiones, con esa nobleza inigualable, y con ese verbo tan sereno como convencido, nos hizo ver que hay que seguir intuiciones e impresiones sin dar por hecho nada que no nos demuestren los datos que hay que ir a buscar, como el mayor de los tesoros, al mundo real de los hablantes, que es el nuestro, pero del que no somos, para suerte del mundo, habitantes únicos.

Este es un texto de esos que uno nunca quisiera tener que escribir, pero es también una oportunidad, que siempre llega tarde, de dar gracias a la vida por quienes nos han enseńado a vivirla, en este caso en los linderos de una profesión, la filología, que hicieron grande para que todos cupiéramos en sus posibilidades. En una tierra como la nuestra, acostumbrada por desgracia a evidenciar infundados complejos que tienen que ver precisamente con nuestra particular forma de hablar español, cobra mayor valor si cabe la obra de quienes, sin esos complejos, convencidos del rigor de su trabajo y de la valiosa materia prima de la que parten, de la absoluta relevancia que para el español tienen estas islas atlánticas, logran con convencimiento situar en el mapa de los estudios más relevantes aquellos que tienen nues- 
tro dialecto por protagonista. Eso hizo José Antonio, al que tanto debemos, al que tanto añoramos. Pero para quien merece tanto, solo tengo palabras como estas que hago suyas y de ustedes, palabras tan sentidas como estas en las que hay más emoción que talento y más gratitud que brillantez. Palabras, al fin y al cabo, como las que toda su vida mimó y rastreó, como las que también se sienten huérfanas desde el pasado diciembre, desde el día en el que merman las noches y crecen los días, y a nosotros nos crecen, al mismo tiempo, la tristeza de perder al maestro, al colega y al amigo, y el orgullo de haber podido contar con su ejemplo único y su esfuerzo generoso, la suerte de haber sido su alumno, su colega y su amigo; la suerte que nadie me arrebatará jamás. Gracias, José Antonio. Gracias.

José Yeray Rodríguez Quintana Universidad de Las Palmas de Gran Canaria Academia Canaria de la Lengua 
